\title{
A simple device for exfoliative cytology of the stomach
}

\author{
ARMANDO L. BASTOS AND F. MADEIRA \\ From the Department of Medicine, Medical School of Lisbon, \\ Hospital of Santa Maria
}

It has been recognized that cytological examination of the stomach is clinically valuable in the diagnosis of cancer in this organ (Raskin, Kirsner, and Palmer, 1958; Schade, 1958) but one of the obstacles in gaining acceptance for this procedure has been the difficulty of obtaining gastric exfoliated cells in good condition for microscopic screening.

The usual method of obtaining gastric cells is gastric lavage with a saline solution through a Levine tube and $100 \mathrm{ml}$. syringe. Forceful irrigation is absolutely necessary to induce the exfoliation of gastric cells. The following is a description of a simple device that produces rapid and forceful washing and allows aspiration of the fluid from the stomach with ease.

\section{APPARATUS}

The apparatus is essentially a vacuum flask and pump (aspiration-pression motor) (Fig. 1) modified so that pressure can be applied without the inconvenience of blowing off the rubber stopper by means of a gadget (Fig. 1B) applied round the neck of the vacuum flask with a steel wire going over the stopper, the free end of the wire locking at the other extremity. The pump is connected to the vacuum flask by means of a rubber connexion which is cut at the points indicated by the arrow on Figure 1B. For aspiration the circuit is closed at the points indicated by the arrow at $\mathrm{A}$.
Figure 2 shows the apparatus and its connexion to the Levine tube by a transparent plastic tube.

\section{PROCEDURE}

The patient, after fasting overnight, sits in an upright position and is intubated with a no. 18 radio-opaque Levine tube up to the $65 \mathrm{~cm}$. mark. Gastric juice is then aspirated with a $100 \mathrm{ml}$. syringe, and usually indicates that the tube is properly placed in the gastric pool. The $p H$ is determined (using Merck universal indicator paper) on the first specimen. The patient then lies on his left side, and the Levine tube is attached to the vacuum flask with the transparent plastic tube. The vacuum flask, which contains $500 \mathrm{ml}$. of Ringer solution, has been left overnight in the refrigerator and when it is ready for use it is placed in a container with ice and placed on the floor. The aspiration-compression motor is attached to the vacuum flask through a rubber connexion. The operator sits near the motor to control the operation of aspiration-compression. Under pressure, $500 \mathrm{ml}$. of Ringer solution is injected in the stomach in 15 to 20 seconds. Compression is off when air bubbles start to appear in the plastic tube connected to the Levine tube, well before they reach the stomach. Generally the gastric wash starts to return to the vacuum flask even before aspiration is applied. Aspiration is then applied and if the Levine tube is well positioned the volume of the return gastric wash is about the same as the amount injected.

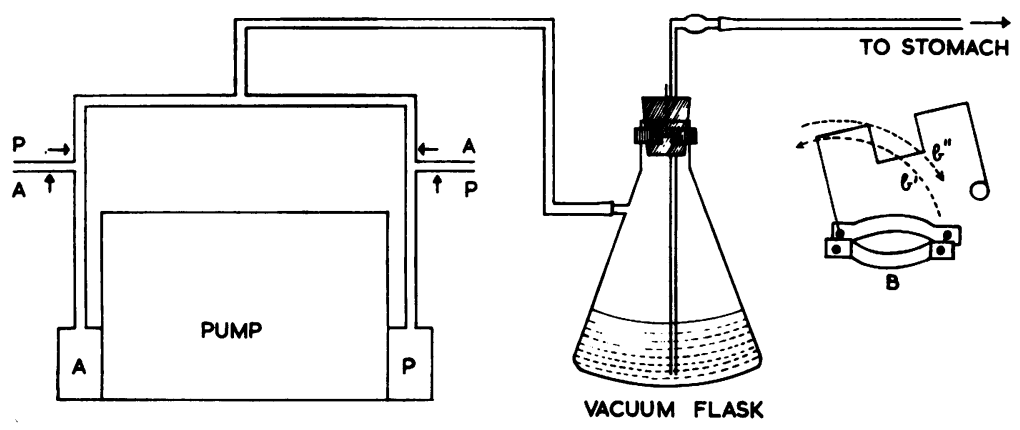

192
FIG. 1. Diagram of the apparatus used for lavage of stomach. A, Aspiration; $P$, Pressure. $\uparrow A$ and $\uparrow P$ (see text). B Two metal bands held together by two screws to be applied around the neck of the vacuum flask. $b^{\prime} b^{\prime \prime}$ represent the movement of the steel wire. 


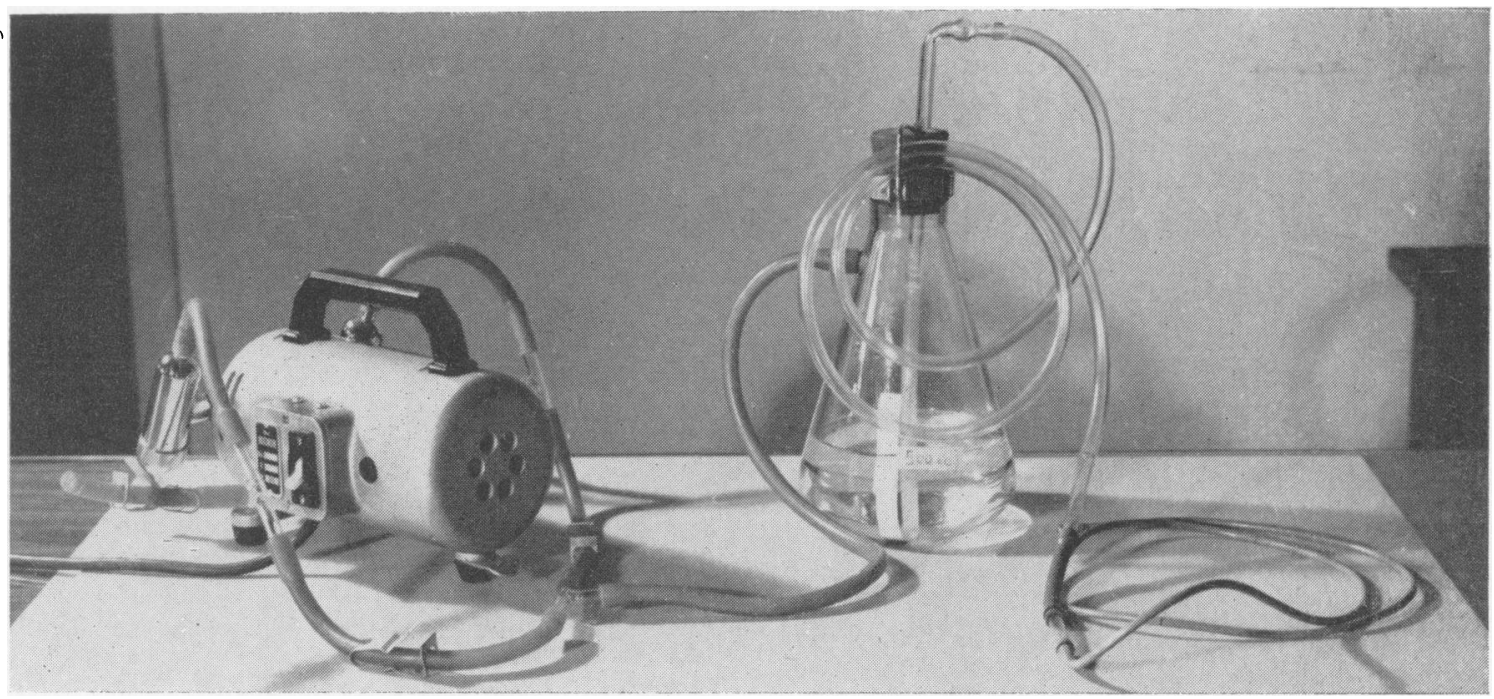

FIG. 2. The equipment used for exfoliative cytology of the stomach.

The operation of pressure-aspiration is repeated twice in each position: left side, dorsal decubitus, right side, ventral decubitus.

Before the patient is asked to change his position $500 \mathrm{ml}$. is injected with the idea that as he moves the solution reaches all the gastric surface mucosa. The final during collection. In 20 cases of gastric cancer, 19 positive gastric smears were obtained. In over 90 patients examined using this device no untoward effects were detected. The quality and amount of the cytological material obtained with this apparatus is impressive (Figs. 3A and 3B).

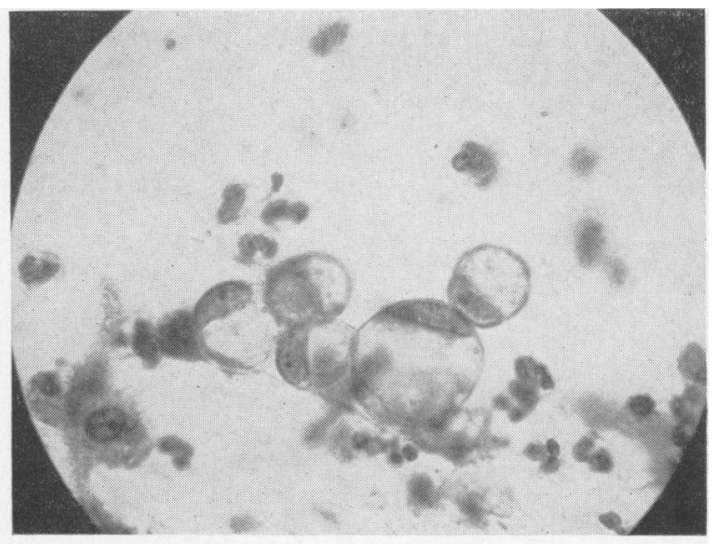

FIG. 3b. aspiration is made with the patient lying on his left side.

By this procedure the collection, including intubation, is over in about 10 minutes.

Some other advantages of this simple and inexpensive device are: If several units of the apparatus are available, three of four gastric washings can be performed within an hour without difficulty or effort by the same individual. The Ringer solution is kept under refrigeration even
We wish to express our appreciation to Mr. Carlos Dias Candido for technical assistance in making the gadget.

\section{REFERENCES}

Raskin, H. F., Kirsner, J. B., and Palmer, W. L. (1958). Exfoliative cytology of the gastro-intestinal tract. In Modern Trends in Gastro-enterology, edited by F. Avery Jones, 2nd ser., pp. 76-91. Butterworth, London.

Schade, R. O. K. (1958). Exfoliative cytology of gastric carcinoma. Brit. med. J., 1, 743-744. 